\title{
Postharvest Quality Measurement and Control of Pears
}

\author{
J. Lammertyn, P. T. Jancsók, ${ }^{*}$ J. De Baerdemaeker ${ }^{*}$ and B. M. Nicolaï \\ Flanders Centre/Laboratory of Postharvest Technology, Catholic University Leuven, \\ Willem de Croylaan 42, B-3001 Leuven, Belgium \\ * Laboratory for Agro-Machinery and Processing, Catholic University Leuven, \\ Kasteelpark Arenberg 30, B-3001 Leuven, Belgium
}

(Received January 23, 2002)

\begin{abstract}
Modern marketing chains continuously stimulate postharvest technology research to develop and improve techniques for measuring internal defects and nutritional and organoleptic fruit quality attributes. Three relatively new non-destructive techniques to assess pear fruit quality and to determine the optimal harvest date-acoustic firmness sensor, electronic nose and near-infrared spectroscopy - are described here. Tomographic techniques like $\mathrm{X}$-ray computer tomography and magnetic resonance imaging were found to be useful for detecting the incidence of core breakdown, a storage disorder in Conference pears. Both techniques were found suitable to discriminate between cavities, affected and unaffected tissue. An attempt was made to detect internal cavities using a technique based on vibrational modal analysis.
\end{abstract}

Keywords: acoustic firmness sensor, core breakdown, electronic nose, near-infrared spectroscopy, tomographic imaging

\section{INTRODUCTION}

With a yearly production of over $500000 \mathrm{t}$, Pyrus communis L. cv. Conference is one of the most important pear cultivars in Europe. In Belgium, Conference pears usually are picked during the first weeks of September, depending on the firmness, ground colour and size, and appropriate postharvest storage conditions need to be applied to maintain good fruit quality over a period of 8 months. Modern marketing chains continuously stimulate postharvest technology research to develop and improve new techniques by which fruit quality (nutritional and organoleptic) can be retained over an increasingly long period. Hereto, a thorough understanding of the structure, biochemistry, physiology and physical properties of the fruit is required. Nowadays, controlled atmosphere is widely applied as storage technique to extend the storage life of pears. However, stored under sub-optimal conditions horticultural produce may be subject to fast quality decay and storage disorders (Wills et al., 1998). Modern non-destructive fruit quality assessment techniques may contribute to monitor and control the ripening reactions which take place during growth and in postharvest storage facilities. This paper focuses on non-destructive measurement techniques for pear quality, including the determination of the optimal harvest date, and the internal defects due to inappropriate storage.

Corresponding author: Jeroen Lammertyn, fax : +32-16-32-29-55, e-mail : jeroen.lammertyn@agr.kuleuven.ac.be 


\section{PRE- AND POSTHARVEST QUALITY CHANGES}

1. Optimal harvest date. The term 'ripening' is a collective noun for the changes taking place in the later stages of maturation and the beginning of senescence. Ripening of fruit involves highly complex changes in physical and chemical properties. Increasing respiration rate, softening, increasing sweetness, aroma and colour changes are among the most important phenomena related to ripening (Kadam et al., 1995). Ripening is closely related to the respiration of the fruit, which is in turn an indicator of the metabolic activity and, thus, storage potential of the fruit. Respiration is the oxidative breakdown of complex substrates normally present in the cell, such as starch, sugars and organic acids to $\mathrm{CO}_{2}$, water and heat. It plays an important role during storage of fruits since it implies the loss of respirable substrate and, hence, the loss of quality (Kader, 1989). Commercial pear cultivars are harvested while hard and green in colour. The determination of the optimal harvest date is very important, as too early harvested fruits have inferior organoleptic quality attributes and too late harvested pears have a shortened storage life and are more susceptible to storage disorders (Lammertyn et al., 2000). In Belgium, Conference pears are harvested in the first half of September. The optimal harvest date is based on a comparison of refractometer values, starch index, colour, acidity and Magness-Taylor firmness with historical data. Recently, De Belie et al. (2000) measured the firmness changes of pear fruit several weeks before and after harvest with the acoustic impulse response technique. Between 3 weeks and 1 week before harvest, the firmness showed a sudden reduction for Conference pears. Afterwards the firmness decreased at a slower rate and could be described by a first-order model. It appeared that the optimal harvest date occurred within about 2 weeks from the measured sudden drop in firmness. Continuation of the firmness measurements after this occasion and the construction of the first-order degradation model allows to predict the optimal harvest date more accurately. They also found that, when pears were picked late, the rate of firmness degradation and weight loss increased.

2. Optimal storage conditions. Once the pears are harvested, storage under appropriate and optimal conditions is necessary to retard the metabolic activity of the fruit and, hence, to retard the deterioration. The design of the optimal storage conditions for pears and other horticultural produce is based on a long tradition of practical experience of different horticultural research institutes all over the world. Much research has been directed towards the determination of the optimum controlled atmosphere (CA) conditions to prevent postharvest deterioration of Bartlett pears (Boersig et al., 1988; Kader, 1989; Wills et al., 1998) and Conference pears (Roelofs and de Jager, 1997; Lammertyn et al., 2000). A reduced $\mathrm{O}_{2}$ concentration ( 1.5 to $2.5 \%)$ and a slightly elevated $\mathrm{CO}_{2}$ concentration $(0.7$ to $1 \%)$ in combination with a low temperature $\left(-1\right.$ to $\left.-0.5^{\circ} \mathrm{C}\right)$ reduces the biochemical changes associated with respiratory metabolism, physical injuries, physiological and pathological breakdown (Brady and Romani, 1988 ; Kerbel et al., 1988 ; Mathooko, 1996). As a general rule, the optimal $\mathrm{O}_{2}$ concentration is considered as the lowest concentration at which no fermentation occurs. The optimal storage temperature is the lowest temperature preventing the pears from freezing damage (Kader, 1989). The determination of the optimal $\mathrm{CO}_{2}$ concentration to store Conference pears is based on a trade off between the preservation of the green colour of the pear and the incidence of $\mathrm{CO}_{2}$ related storage disorders. In Belgium, the following advice was given by Flanders Centre of Postharvest Technology for CA storage of Conference pears over the last 3 years : $0.5-0.7 \% \mathrm{CO}_{2}, 2-3 \% \mathrm{O}_{2}$ and a temperature between -1 and $-0.5^{\circ} \mathrm{C}$.

3. Storage disorders. The application of too extreme artificial (modified or controlled) atmospheres and/or bad temperature management can disturb the biochemical metabolic 
pathways of the fruit resulting in irreversible physiological damage and, hence, large economic losses. The most common physiological storage disorders in pears are scald (superficial and senescent), vascular breakdown and core breakdown (Kadam et al., 1995 ; Wills et al., 1998). The latter is a $\mathrm{CO}_{2}$ related physiological disorder which typically occurs in Conference pears stored under too extreme controlled atmosphere conditions. It is characterised by softening and browning of the tissue near the core and it is often accompanied with the development of cavities. None of these symptoms can be observed from the outside. The time course of internal browning and the appearance of cavities suggests that cavities arise from the brown areas (Roelofs and de Jager, 1997). Figure 1 depicts pears affected by core breakdown disorder. The brown discoloured tissue is situated around the core in the thickest part of the pear and its boundaries are parallel to the boundaries of the pear. Subsequently, cavities start to grow randomly, initiated by an unknown trigger, at the expense of this brown tissue which further dehydrates (Lammertyn et al., 2001).

Several factors directly or indirectly influence the development of core breakdown disorder. These factors can be subdivided into two categories: pre- and postharvest factors. "Pre-harvest factors" include fruit setting, number and position of the fruits on the tree, weather conditions during growth, presence/absence of a core (parthenocarpic fruits), orchard and tree characteristics and harvest date (Roelofs and de Jager, 1997 ; Lammertyn et al., 2000). These factors are hard to control or cannot be controlled at all. "Post-harvest factors" include storage temperature and gas atmosphere, storage time and duration of the cooling period preceding CA storage. Unlike pre-harvest factors these factors can be controlled, and in combination with insight in the physiology of the disorder, they might be fine tuned in the future such that pears produced under sub-optimal pre-harvest conditions (e.g., parthenocarpic pears) can be prevented from browning. The interaction between pre- and postharvest factors determines the intrinsic fruit quality attributes like sugar content, firmness, acidity, vitamin C content, tissue and skin gas diffusivity properties, which are believed to influence the incidence of core breakdown in pears (Kader, 1989; Lentheric et al., 1999; Veltman et al., 1999).

Logistic regression models were built to identify the factors influencing core breakdown disorder (Lammertyn et al., 2000). The statistical analyses showed that the incidence of this pear disorder depends on several intrinsic and external variables, in a more complex way than was described and assumed before in the literature. In general, an increased $\mathrm{CO}_{2}$ concentration, a longer storage time and a low $\mathrm{O}_{2}$ concentration result in more brown and cavities. Over-mature picked pears are by far more susceptible to core breakdown. Delayed controlled atmosphere up to $50 \mathrm{~d}$ or longer reduced the number of affected pears considerably, even when the pears were harvested after the commercial picking date. Inclusion of the intrinsic parameters improved the models only slightly, since most of the ripeness parameters are correlated with storage time. A strong relation was found between the pear size (weight) and the susceptibility to develop cavities and internal browning. The statistical analysis also supported the hypothesis that cavities grow at the expense of brown tissue. An affected pear first develops brown spots, which grow in time, dehydrate and later on disappear completely to form cavities (Lammertyn et al., 2000). In the future, more research is needed to include pre-harvest factors like hours of sunshine, age of the trees, soil composition, etc. and intrinsic factors like vitamin C concentration, SSC and firmness at the beginning of storage, into the model.

\section{NON-DESTRUCTIVE QUALITY MEASUREMENTS}

Non-destructive quality measurements may be helpful to improve the accuracy of harvest date determination and quality monitoring. During storage it is important to monitor the 


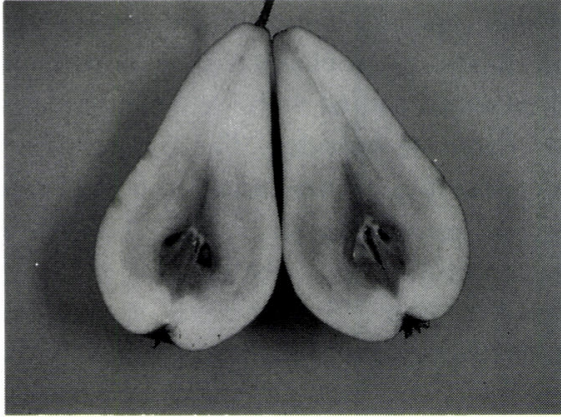

Fig. 1 Pear affected by core breakdown. The brown tissue in the centre of the fruit is invisible from the outside.

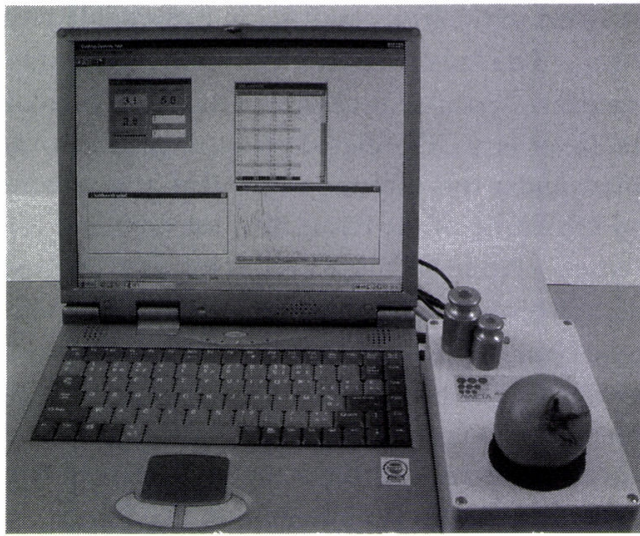

Fig. 2 Acoustic firmness sensor (AFS, AWETA BV, The Netherlands) to measure firmness of horticultural produce.

response of the fruit to the applied storage atmosphere. This response, combined with a feedback to the storage control system, might improve the fruit quality retention during storage. Five relatively new techniques for non-destructive assessment of fruit quality are highlighted below. Most of them are not yet in commercial use, but are valuable and promising tools in the future for the accurate determination of the optimal picking date and in quality monitoring during storage.

\section{Acoustic response technique}

Firmness is a quality property which is related to the mechanical properties of the fruit flesh. For spherical fruits the acoustic response method is often used to measure firmness. In this method the fruit is excited using an impact hammer and the response signal is captured using a microphone, analyzed and the resonant frequencies are related to the firmness of the fruit (Fig. 2). These method has recently been adapted to non-spherical fruits like pears (De Belie et al., 2000 ; Jancsók et al., 2001a). By means of experimental modal analysis and finite element simulations the vibration modes of differently shaped pears were studied. It was found that 3 different vibration modes can be used in the quality measurements. The modes are the compression, the bending and the oblate-prolate modes. In compression mode the whole body of the pear is vibrating in longitudinal direction. It becomes shorter and longer as the pear is compressed and elongated. In bending mode, the top part of the pear is deformed and bent. In oblate-prolate mode the bottom part of the pear becomes flatter in one direction and wider in the perpendicular direction. It was found (Dewulf et al., 1999) that by measuring different mode-shapes the properties of the different parts of the pear could be estimated.

\section{Electronic nose}

During growth, ripening and storage, the physiological state of the pears changes as a result of metabolic activity such as respiration. Accordingly, the volatile pattern emanating from the fruit changes with state of ripeness. Sensing the aromatic volatiles emitted by the fruit using electronic olfactory systems offers an alternative technique to measure nondestructively the fruit quality or state of ripeness (Brezmes et al., 2000). With an electronic nose, Brezmes et al. (2000) were able to classify pear fruit into three different states of ripeness 
with very good accuracy. Oshita et al. (2000) evaluated the odor pattern emitted by pears in different physiological states. They found that seven volatile compounds characterize the odor of the pear in each physiological state. Young et al. (1999) and Saevels et al. (2001) used the electronic nose as an potential maturity indicator for apples. Saevels et al. (2001) observed a high correlation between the signals generated with the electronic nose and the physiological maturity and Streif index of apple fruit. The latter is a commonly used index in Europe to determine the optimal harvest date (Streif, 1996).

\section{Near-infrared reflectance (NIR) spectroscopy}

The last decade, near-infrared reflectance spectroscopy (NIRS) has been evaluated extensively to probe non-destructively the interior quality attributes of horticultural produce. The advantage of this technique are ample: speed of measurement, simultaneous measurement of different attributes and repeated measurements on the same sample. The latter implies that quality can be followed on the same fruit during growth and storage. NIRS has been applied to predict and classify fruits according to their soluble solids content, organic acid content, dry matter and ethanol content and firmness in several horticultural commodities (Kawano et al., 1992 ; Lammertyn et al., 1998 ; McGlone and Kawano, 1998 ; Kays, 1999). More recently, Peirs et al. (2000) applied NIRS to predict apple maturity. They were able to predict with a reasonable accuracy the optimal harvest date. This technique will be applied at the Flanders Centre of Postharvest Technology in Belgium to advise the growers on the harvest date. However, to the authors knowledge, for an unknown reason, not much information exists about NIR quality measurements on pears.

\section{Tomographic imaging of core breakdown}

Two non-destructive tomographic techniques are useful for the detection of internal defects in fruit: X-ray computer tomography (X-ray CT) and magnetic resonance imaging (MRI). X-ray CT has been explored several times to study the interior of horticultural produce. The intensities and contrasts on the X-ray $\mathrm{CT}$ images are mainly based on differences in mass density and absorption of the material. Due to the high moisture content in fruit and vegetables, water dominates X-ray absorption (Abbott, 1999). Most internal disorders like woolliness in nectarines, hollow heart in potato and watercore in apples affect the density of the internal tissue and, hence, are detectable by means of X-ray measurements (Brecht et al., 1991 ; Tollner et al., 1992 ; Thomas et al., 1993 ; Schatzki et al., 1997 ; Barcelon et al., 1999). Magnetic resonance imaging (MRI) is another non-destructive technique that allows to monitor the development of internal defects and storage disorders over time. ${ }^{1} \mathrm{H}$ MRI employs static magnetic fields and radio frequencies in order to obtain images of proton mobility in biological systems. Basically, the signal comes from the aqueous fraction in the sample. The first application of MRI in a horticultural context was reported by Wang et al. (1988), who studied watercore in apples. Since then, MRI has been applied as a qualitative tool to detect core breakdown in 'Bartlett' pears (Wang and Wang, 1989), to detect void spaces, worm damage and bruises in fruits (Zion et al., 1995; Saito et al., 1996), watercore and internal browning in apples (Clark and Burmeister, 1999; Gonzalez et al., 2001) and woolly breakdown in nectarines (Sonego et al., 1995). Nowadays, interest in quantitative MRI (QMRI) grows. In QMRI, the static and dynamic properties of aqueous protons, such as relaxation times and diffusivity, are related to the physiological processes in fruit.

Lammertyn et al. (2001) applied X-ray CT and MRI to study the spatial distribution of core breakdown disorder symptoms in 'Conference' pears and to study the time course of core breakdown during storage under disorder inducing conditions. Both techniques were suited to detect brown discoloured tissue and cavities in affected pears. A semi-automatic image 


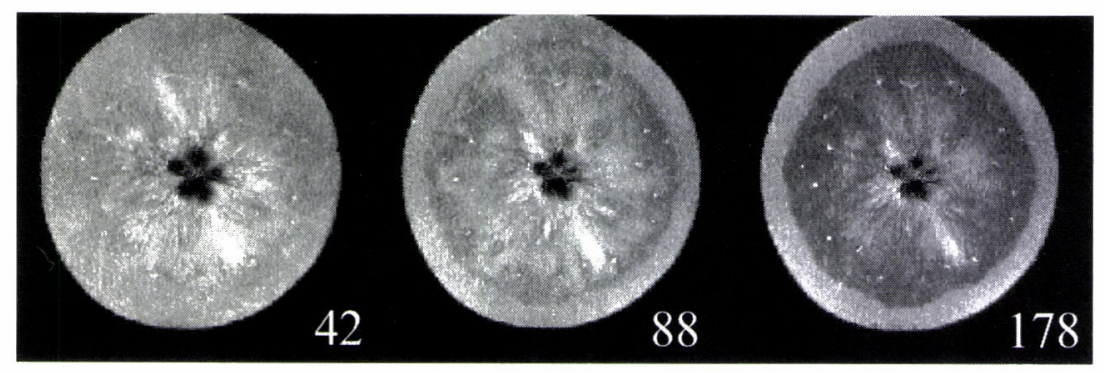

Fig. 3 Three MR images of one pear slice taken during storage under disorder inducing conditions. The browning pattern (darker intensities) is radial. The numbers indicate the storage time expressed as days after harvest.

processing algorithm, based on threshold values, was developed to determine the area percentage of affected (brown) and unaffected tissue as well as the cavity and core area per slice. With this technique, X-ray CT scans and MRI slices were compared qualitatively and quantitatively with each other and with digital photographs of the corresponding actual pear slices. MRI seemed to yield a better contrast between affected and unaffected tissue than X-ray CT scans. For all three techniques the area percentage brown tissue per slice increased with the diameter of the pear. However, it was systematically underestimated with X-ray CT and MRI, compared to the actual slices, because of a region in the centre of the pear slice which was brown on the real slice but was not detected as brown by the tomographic imaging techniques. This difference was ascribed to the different physical properties which were measured by the respective techniques. However, the area percentage cavity corresponded very well for all techniques.

MRI was found to be the most sensitive technique to study the development of core breakdown disorder during postharvest storage. Following the change in image contrast between healthy and brown tissue on the MR images during storage, incipient browning was detected after 2 months of storage. Two patterns of browning, a radial and a local one, were observed. Both patterns did not evolve or grow spatially, but only increased their contrast to healthy tissue, during storage (Fig. 3). Eventually, cavities grew at the expense of the brown dried tissue. The contours of the affected tissue were always parallel to the pear boundaries, suggesting a relation to gas diffusion properties of tissue and skin. In future work, this typical pattern of browning may also be related to the different tissue structures in pears, which may have a different sensitivity with respect to core breakdown. The time course experiment has shown that X-ray CT cannot detect incipient browning as soon as MRI can.

\section{Vibration analysis to detect cavities}

As the acoustic response technique was found applicable to measure the firmness of pears, a study was made to examine the possibility to detect internal cavities by vibration analysis (Jancsók et al., 2001b). To simulate the vibration behaviour of affected pears, finite element models were developed and validated. The finite element meshes are based on shape measurements of real hollow fruits. The previously mentioned X-ray CT scans were used to build a finite element mesh of the affected pear (Fig. 4). The contour information was extracted from the CT scans and three-dimensional geometrical models were constructed.

With a commercial finite element program the resonance frequencies were calculated by finite element modal analysis. The finite element meshes then were modified and the cavities were removed from the models. Since the mass influences the resonance frequencies to a large 


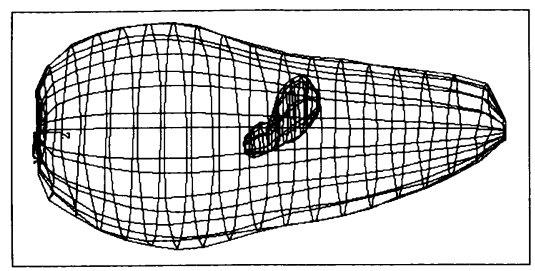

Fig. 4 3D geometrical model of the pear with a cavity.

extent, the resonance frequencies calculated with the cavity and without the cavity were made comparable by normalisation. The results of the simulations were compared and it was found that the differences between the resonance frequencies with and without the cavity are small. This means that it is almost impossible to distinguish between hollow and not hollow pears just based on the resonance frequencies. However, the difference between frequencies of the hollow and not hollow pears are not the same for all the modes. There are vibration modes where the resonance frequency depend on the direction of the vibration. Differences were also found in those direction dependent modes. This possibly allows the detection of the cavities.

According to the result of the simulation, vibration measurements were carried out on affected fruits to examine the vibration pattern from different directions. In the vibration measurements the pattern of consecutive impact at different sides of the pear were compared. In case of a symmetric pear the patterns of the spectrum of the impact from different directions should be the same. If there is a hole inside the fruit, which breaks the symmetry, the patterns will be different. The measurements of a symmetric pear with a long asymmetric hole inside showed that the consecutive impacts resulted in different patterns in bending and oblateprolate modes. It is hard to detect the cavity if it is exactly in the centrum because the consecutive impacts give the same results. If the cavity is in the bottom part of the pear it can cause the consecutive impacts at different positions to be different in the oblate prolate mode.

\section{CONCLUSIONS}

In this article a survey was given on how quality can be monitored in pears before harvest, at harvest and during storage. Emphasis was put on non-destructive measurement techniques because of the many advantages : individual fruits can be measured repeatedly and monitored over time without sample preparation. The importance of the optimal harvest date and storage conditions on fruit quality and development of storage disorders was illustrated. In addition to the existing quality measurement techniques, the electronic nose, the acoustic firmness sensor and NIRS offer information about the physiological state of the fruit and can be used to control and adjust the storage conditions. When stored under sub-optimal atmospheres the fruit may develop core breakdown. The factors causing this storage disorders were identified and summarized in a graphical user interface for easy access. It was found that the incipient tissue browning could be detected in an early stage by means of X-ray CT and MRI. However, the latter having a higher power to discriminate between cavities, affected and unaffected tissue. Attempts have been made to detect internal cavities using a modal analysis. Future research is needed to implement these non-destructive techniques to measure internal fruit quality on commercial grading lines and decision support systems.

The Flanders Centre of Postharvest Technology is financially supported by the VBT, the Catholic University Leuven, the Flemish Government and the Ministry of SME and Agriculture. 


\section{REFERENCES}

Abbott, J. A. 1999. Quality measurement of fruits and vegetables. Postharvest Biol. Technol. 15 : 207225.

Barcelon, E. G., Tojo, S., Watanabe, K. 1999. X-ray CT imaging and quality detection of peach at different physiological maturity. Trans. ASAE 42: 435-441.

Boersig, M. R., Kader, A. A., Romani, R. J. 1988. Aerobic-anaerobic respiratory transition in pear fruit and cultured pear fruit cells. J. Am. Soc. Hortic. Sci. 113: 869-873.

Brady, C. J., Romani, R. J. 1988. Respiration and protein synthesis in nongrowing cultured pear fruit cells in response to ethylene and modified atmosphere. Plant Physiol. 87 : 571-576.

Brecht, J. K., Shewfelt, R. L., Garner, J. C., Tollner, E. W. 1991. Using X-ray-computed tomography to non-destructively determine maturity of green tomatoes. HortScience 26 : 45-47.

Brezmes, J., Llobet, E., Vilanova, X., Saiz, G., Correig, X. 2000. Fruit ripeness monitoring using an electronic nose. Sensors Actuators B 69: 223-229.

Clark, C. J., Burmeister, D. M. 1999. Magnetic resonance imaging of browning development in 'Braeburn' apple during controlled atmosphere storage under high $\mathrm{CO}_{2}$. HortScience 34: 915-919.

De Belie, N., Schotte, S., Lammertyn, J., Nicolaï, B. M., De Baerdemaeker, J. 2000. Firmness changes of pear fruit before and after harvest with the acoustic impuls response technique. J. Agric. Eng. Res. 77 : 183-191.

Dewulf, W., Jancsók, P., Nicolaĩ, B., De Roeck, G., Briassoulis, D. 1999. Development of an experimental method for determining the firmness of a pear using finite element modal analysis. J. Agric. Eng. Res. 74 : 217-224.

Gonzalez, J. J., Valle, R. C., Bobroff, S., Biasi, W. V., Mitcham, E. J., McCarthy, M. J. 2001. Detection and monitoring of internal browning development in 'Fuji' apples using MRI. Postharvest Biol. Technol. 22 : 179-188.

Jancsók, P. T., Clijmans, L., Nicolaï, B. M., De Baerdemaeker, J. 2001a. Investigation of the effect of shape on the acoustic response of conference pears by finite element modelling. Postharvest Biol. Technol. 23 : 1-12.

Jancsók, P. T., Lammertyn, J., Nicolaï, B. M., De Baerdemaeker, J. 2001b. Internal defect detection of pears by impulse response method. 6th International Symposium on Fruit, Nut, and Vegetable Production Engineering, Sept. 11-14, Potsdam, Germany.

Kadam, S. S., Dhumal, A., Shinde, N. N. 1995. Pear. In "Handbook of Fruit Science and Technology" (ed. by Salunkhe, D. K., Kadam, S. S.). Marcel Dekker Inc., New York, p 183-202.

Kader, A. A. 1989. Mode of action of oxygen and carbon dioxide on postharvest physiology of 'Bartlett' pears. Acta Hortic. 258 : 161-167.

Kawano, S., Watanabe, H., Iwamoto, M. 1992. Determination of sugar content in intact peaches by near infrared spectroscopy with fibre optics in interactance mode. J. Jpn. Soc. Hortic. Sci. 61 : 445-451.

Kays, S. J. 1999. Non-destructive quality evaluation of intact, high moisture products. NIR News 10 : 12-15.

Kerbel, E. L., Kader, A. A., Romani, R. J. 1988. Effects of elevated carbon dioxide concentrations on glycolysis in intact 'Bartlett' pear fruit. Plant Physiol. 86 : 1205-1209.

Lammertyn, J., Nicolaī, B. M., De Smedt, V., De Baerdemaeker, J. 1998. Non-destructive measurement of acidity, soluble solids and firmness of Jonagold apples using NIR-spectroscopy. Trans. ASAE 41 : 1089-1094.

Lammertyn, J., Aerts, M., Verlinden, B. E., Schotmans, W., Nicolaï, B.M. 2000. Logistic regression analysis of factors influencing core breakdown in 'Conference' pears. Postharvest Biol. Technol. 20 : 25-37.

Lammertyn, J., Jancsók, P., Dresselaers, T., Van Hecke, P., Wevers, M., De Baerdemaeker, J., Nicolaï, B. M. 2001. X-ray CT and magnetic resonance imaging to study the development of core breakdown in 'Conference' pears. ASAE Annual International Meeting, July 29-August 1, Sacramento, California, Paper 016037 p 11.

Lentheric, I., Pinto, E., Vendrell, M., Larrigaudiere, C. 1999. Harvest date affects the anti-oxidative systems in pear fruits. J. Hortic. Sci. Biotechnol. 74 : 791-795.

Mathooko, F. M. 1996. Regulation of respiratory metabolism in fruits and vegetables by carbon 
dioxide. Postharvest Biol. Technol. 9 : 247-264.

McGlone, V., Kawano, S. 1998. Firmness, dry matter and soluble solids assessment of postharvest kiwifruit by NIR-spectroscopy. Postharvest Biol. Technol. 13 : 131-141.

Oshita, S., Shima, K., Haruta, T., Seo, Y., Kawagoe, Y., Nakayama, S., Takahara, H. $2000 . \quad$ Discrimination of odors emanating from 'La France' pear by semi-conducting polymer sensors. Comput. Electron. Agric. 26 : 209-216.

Peirs, A., Lammertyn, J., Ooms, K., Nicolaï, B. M. 2000. Prediction of the optimal picking date of different apple cultivars by means of VIS/NIR-spectroscopy. Postharvest Biol. Technol. 21 : 189-199.

Roelofs, F. P., de Jager, A. 1997. Reduction of brownheart in 'Conference' pears. Controlled Atmosphere Research Conference, July 13-18, University of California, Davis, USA, Proceedings Volume 2: Apples and Pears (ed. by Mitcham, E.) p 138-144.

Saevels, S., Di Natale, C., Nicolaï, B. M. 2001. Electronic nose technology to evaluate picking date of apples, 6th International Symposium on Fruit, Nut and Vegetable Production Engineering, September 11-14, Potsdam, Germany (in press)

Saito, K., Miki, T., Hayashi, S., Kajikawa, H., Shimada, M., Kawate, Y., Nishizawa, T., Ikegaya, D., Kimura, N., Takabatake, K., Sugiura, N., Suzuki, M. 1996. Application of magnetic resonance imaging to non-destructive void detection in watermelon. Cryogenics 36: 1027-1031.

Schatzki, T. F., Haff, R. P., Young, R., Can, I., Le, L. C., Toyofuku, N. 1997. Defect detection in apples by means of X-ray imaging. Trans. ASAE $40: 1407-1415$.

Sonego, L., Ben-Arie, R., Raynal, J., Pech, J. C. 1995. Biochemical and physical evaluation of textural characteristics of nectarines exhibiting woolly breakdown: NMR imaging, X-ray computed tomography and pectin composition. Postharvest Biol. Technol. 5 : 187-198.

Streif, J. 1996. Optimum harvest date for different apple cultivars in the 'Bodensee' area. In "COST 94. The Postharvest Treatment of Fruit and Vegetables: Determination and Prediction of Optimum Harvest Date of Apples and Pears" (ed. by de Jaeger, A., Johnson, D., Hohn, E.). ECSC-EC-EAEC, Brussels, p 15-20.

Thomas, P., Saxena, S. C., Chandra, R., Rao, R., Bhatia, C. R. 1993. X-ray imaging for detecting spongy tissue, an internal disorder in fruits of 'Alphonso' mango (Mangifera indica L.). J. Hortic. Sci. 68 : 803-806.

Tollner, E. W., Hung, Y. C., Upchurch, B. L., Prussia, S. E. 1992. Relating X-ray absorption to density and water content in apples. Trans. ASAE $35: 1921-1928$.

Veltman, R. H., Sanders, M. G., Persijn, S. T., Peppelenbos, H. W., Oosterhaven, J. 1999. Decreased ascorbic acid levels and brown core development in pears (Pyrus communis L. cv. Conference). Physiol. Plant. 107 : 39-45.

Wang, C. Y., Wang, P. C. 1989. Nondestructive detection of core breakdown in 'Bartlett' pears with nuclear magnetic resonance imaging. HortScience 24 : 106-109.

Wang, S. Y., Wang, P. C., Faust, M. 1988. Non-destructive detection of watercore in apple with nuclear magnetic resonance imaging. Sci. Hortic. $35: 227-234$.

Wills, R., McGlasson, B., Graham, D., Joyce, D. 1998. Postharvest, an Introduction to the Physiology and Handling of Fruit, Vegetables and Ornamentals. CAB International, Wallingford Oxon.

Young, H., Rossiter, K., Wang, M., Miller, M. 1999. Characterization of Royal Gala apple aroma using electronic nose technology-potential maturity indicator. J. Agric. Food Chem. 47 : 5173-5177.

Zion, B., Chen, P., McCarthy, M. J. 1995. Detection of bruises in magnetic resonance images of apples. Comput. Electron. Agric. 13 : 289-299. 